\title{
Process OR PRODUCT? BUILDING STUDENT ENGINEERS' INFORMATION LITERACY SKILLS
}

\author{
Norma Godavari and Betty Braaksma \\ Engineering Library \\ University of Manitoba \\ Winnipeg, MB Canada
}

\begin{abstract}
Information literacy, defined as the ability to effectively find, use and evaluate information in any medium, is embedded in many, if not most of the CEAB accreditation standards but it remains largely unknown in engineering. Traditional evaluation persists: the research product (such as papers, projects, reports) is rewarded, while the research process is barely acknowledged or ignored completely. The ubiquitous availability of online information has contributed to this perception. In spite of mounting evidence to the contrary, the myth of the "digital native" still lulls educators into believing that all students are expert searchers who have an intuitive grasp of the academic research process.

We propose to show how information literacy, which includes visual and digital literacies, is essential to engineering students' success. We will present the basic fundamentals of information literacy within a professional school such as engineering. We will also discuss recent changes and its impacts on information literacy in an engineering technical communications class.
\end{abstract}

